\title{
Concentrations of luteinizing hormone and oestradiol in plasma and response to injection of gonadotrophin- releasing hormone analogue at selected stages of anoestrus in domestic bitches
}

\author{
I. A. Jeffcoate \\ Department of Veterinary Physiology, University of Glasgow Veterinary School, Bearsden Road, \\ Glasgow, UK
}

\begin{abstract}
Summary. Concentration of plasma luteinizing hormone ( $\mathrm{LH})$ and oestradiol concentrations and responses to a standard challenge with a gonadotrophin-releasing hormone (GnRH) analogue were measured at certain stages of anoestrus during consecutive cycles in five beagle bitches. Blood samples were collected every $20 \mathrm{~min}$ for $6 \mathrm{~h}$ followed immediately by injection of GnRH analogue $(0 \cdot 16 \mu \mathrm{g}$ i.v. $)$ and collection of further samples after 10,20,40 and $60 \mathrm{~min}$. Five, 10,17 and three such sampling sequences were obtained during the luteal phase, transition to anoestrus, anoestrus and pro-oestrus respectively (i.e. 154-71, 114-44, 85-11 and 7-1 days before the preovulatory LH peak, respectively). Pulsatile $\mathrm{LH}$ secretion occurred spontaneously at all stages of the luteal phase and anoestrus and there was no effect of cycle stage on mean $\mathrm{LH}$ concentration or variability. In contrast, oestradiol could not be detected in most samples from early and mid-anoestrus until approximately one month before the preovulatory LH peak, after which average oestradiol concentration and between sample variability appeared to increase. Mean ( \pm SEM) oestradiol concentration for all samples collected from $100-75,74-50,49-25,24-10$ and 9-1 days before LH peak was $1 \cdot 4 \pm 0 \cdot 1,1 \cdot 3 \pm 0 \cdot 1$, $2 \cdot 4 \pm 0 \cdot 3,11 \cdot 0 \pm 1 \cdot 4$ and $36 \cdot 0 \pm 3 \cdot 2 \mathrm{pg} \mathrm{ml}^{-1}$, respectively. Plasma LH concentration increased in all bitches after $\mathrm{GnRH}$ analogue injection $\left(2.7 \pm 0.7 \mathrm{ng} \mathrm{ml}^{-1}\right.$ at $t=0$, $12.5 \pm 1.0 \mathrm{ng} \mathrm{ml}^{-1}$ at $t=10 \mathrm{~min}$, mean $\pm \mathrm{SEM}, n=35$ ) regardless of cycle stage. Small increases in oestradiol levels were observed after $\mathrm{GnRH}$ analogue injection (range 5-15 $\mathrm{pg} \mathrm{ml}^{-1}$ ) in early and mid-anoestrus but responses could not be discriminated from background fluctuations during the last month of the cycle. The results suggest that termination of anoestrus is dependent on improved ovarian responsiveness to gonadotrophins since pituitary gonadotrophin secretion is maintained throughout anoestrus.
\end{abstract}

Keywords: anoestrus, dog, luteinizing hormone, oestradiol

\section{Introduction}

The oestrous cycle of bitches is considerably longer than that of most other domestic animals, mostly because of a long luteal phase and then an obligatory period of anoestrus, which together last at least 5 months. Although it is generally recognized that plasma progesterone concentration drops slowly during the late luteal phase and then remains low during anoestrus (Concannon, 1986a), there is less agreement about the other hormones likely to be involved in the control of anoestrus. Thus plasma oestrogen concentration has been shown to be high but somewhat variable during anoestrus with either no detectable changes occurring at the onset of pro-oestrus (Graf, 
1978 ) or with a decrease at this time (Olson et al., 1982). Earlier work, however, had indicated low plasma oestrogen concentrations throughout anoestrus (Hadley, 1975). Olson et al. (1982) measured plasma luteinizing hormone $(\mathrm{LH})$ and follicle-stimulating hormone (FSH) concentrations and showed that LH levels remained low until late in anoestrus, after which increased values could be detected; FSH concentrations were high throughout anoestrus and then decreased during pro-oestrus. Concannon et al. (1986b) collected sequential blood samples every 20 min for $7 \mathrm{~h}$ and showed that $\mathrm{LH}$ secretion was pulsatile with a pulse frequency which increased during anoestrus to reach a maximum 10-25 days before the onset of oestrus. The results from the earlier studies described above, which used weekly or daily sampling protocols, may therefore be misleading since single samples are probably inappropriate for measuring hormones, the plasma concentrations of which are likely to show acute fluctuations. The present study measured plasma LH and oestradiol concentrations simultaneously in multiple samples collected at various defined stages of the cycle to characterize the activity of the pituitary-ovarian endocrine axis during anoestrus and the transition into pro-oestrus.

\title{
Materials and Methods
}

\begin{abstract}
Animals
Five multiparous beagle bitches, approximately 5 years old and weighing $12-13 \mathrm{~kg}$, were used. They were housed individually in a kennel with other dogs and were generally allowed to exercise outdoors in pairs. Natural daylight was supplemented with artificial light from 09:00-17:00 h during the winter. Oestrous cycles were monitored using the following criteria: (a) plasma progesterone profiles, which were established using weekly blood samples; (b) daily observation for onset of vulvular bleeding and behavioural changes associated with onset of pro-oestrus and oestrus; and (c) identification of preovulatory LH peaks, which were obtained by analysis of daily blood samples collected from the start of vulvular bleeding, that is the first day of pro-oestrus.
\end{abstract}

\section{Blood sampling procedure}

Daily or weekly blood samples were obtained by jugular venepuncture. More frequent samples were collected using an indwelling cannula fitted as follows. Polythene tubing (i.d. $0.58 \mathrm{~mm}$, o.d. $0.96 \mathrm{~mm}$; Portex Ltd, Hythe, Kent, UK) was inserted into an external jugular vein to a depth of $\approx 6 \mathrm{~cm}$, via a $16 \mathrm{G}$ hypodermic needle (Monoject, St Louis, MO, USA). The free end of the cannula was passed through the centre of a $6 \mathrm{~cm}$ square of Elastoplast (Smith \& Nephew Ltd, Hull, UK), adhesive side outwards, and secured to the hair of the neck with additional contact adhesive. Another square of Elastoplast was stuck over the first, thus sandwiching and securing the cannula. The free end of the cannula was trimmed close to the plaster and fitted with a blunt $23 \mathrm{G}$ needle stoppered with the tip of a $1 \mathrm{ml}$ syringe and the device was kept patent with heparinized saline (30 i.u. $\left.\mathrm{ml}^{-1}\right)$. Samples were collected at 20 min intervals for $6 \mathrm{~h}(10: 00-16: 00 \mathrm{~h})$. An analogue of gonadotrophin-releasing hormone (D-Ser (But) ${ }^{6}$ Des $\mathrm{Gly}-\mathrm{NH}_{2}{ }^{10} \mathrm{Gn}-\mathrm{RH}$ ethylamide, 'Receptal', Hoechst UK Ltd, Milton Keynes, Bucks, UK) was then injected via the cannula (0-16 $\mu \mathrm{g}$ per $\operatorname{dog}$ ) and further blood samples were collected 10,20,40 and $60 \mathrm{~min}$ later. A total of five, 10, 17 and three such sampling sequences were collected during the luteal phase, transition to anoestrus, anoestrus and pro-oestrus respectively (i.e. 154-71, 114-44, 85 -11 and 7-1 days before the preovulatory $\mathrm{LH}$ peak, respectively). All plasma was separated promptly and stored frozen until analysed by radioimmunoassay.

\section{Radioimmunoassay}

Plasma LH concentration was determined by double antibody radioimmunoassay as described previously (Jeffcoate \& Lindsay, 1989) but using a canine LH standard (LER-1685-1, provided by L. E. Reichert, Albany Medical College, NY, USA) and a primary antibody (R15I) raised in this laboratory in a rabbit against ovine LH (NIH-oLH-S25, National Hormone and Pituitary Program, NIADDK, Bethesda, MD, USA). This antiserum was used and displacement of ${ }^{125}$ I-labelled LH tracer by canine LH paralleled displacement curves obtained using equal masses of ovine LH and bovine LH (USDA-bLH-B-5). Antibody crossreaction with ovine growth hormone (oGH) (NIH-oGH-13) was $1.3 \%$ and was less than $0.1 \%$ against ovine follicle-stimulating hormone (oFSH) (NIH-oFSH16), ovine thyroid-stimulating hormone (oTSH) (NIH-oTSH-9) and ovine prolactin (NIH-oPRL-1-2). Additional information on antibody specificity in dog samples was obtained by collecting plasma samples at 20 min intervals from two bitches before and after injection of growth-hormone-releasing hormone (GHRH, Sigma Chemical Co., Poole, Dorset, UK, $5 \mu \mathrm{g}$, i.v.) followed an hour later by thyrotrophin-releasing hormone (TRH, Sigma, $100 \mu \mathrm{g}$, i.v.) and then $2 \mathrm{~h}$ later by GnRH ( $(0.16 \mu \mathrm{g}$, i.v.). Plasma LH concentration was determined in these samples using antiserum 
R151 and a previously validated antiserum (G. D. Niswender no. 15). These doses of TRH and GHRH have been shown to stimulate TSH and GH secretion respectively in the dog and other species (Nett et al., 1975; Lance et al., 1984). In neither assay system was there an apparent increase in LH immunoreactivity after TRH or GHRH injection but surges in plasma LH concentration were observed in both animals, and by both assays, soon after GnRH injection and also in one bitch $40 \mathrm{~min}$ before GHRH injection. Increasing volumes of plasma from an ovariectomized bitch (5 $200 \mu \mathrm{l}$ ) displaced ${ }^{125} \mathrm{I}$-labelled oLH in a dose-dependent manner parallel to the canine LH standards. Recoveries of 2, 5 or $10 \mathrm{ng}$ canine LH standard added to canine plasma and assayed in triplicate were 91,95 and $93 \%$, respectively after adjusting for plasma LH content. Assay sensitivity $\left(2 \times\right.$ sD of total binding) was $0 \cdot 21 \pm 0.02 \mathrm{ng} \mathrm{ml}^{-1}(n=5)$. Intra- and interassay coefficients of variation for a plasma pool containing high $\mathrm{LH}$ concentration were 5 and $8 \%$, respectively.

Plasma progesterone concentration was determined using a double-antibody radioimmunoassay after ether extraction. The primary antibody (provided by B. Cook, the Royal Infirmary, Glasgow, UK) was raised in a sheep against $11 \alpha$-hydroxyprogesterone hemisuccinate-BSA. Crossreaction with $11 \alpha$-hydroxyprogesterone, 11 -deoxycorticosterone, $17 \alpha$-hydroxyprogesterone and $20 \alpha$-hydroxypregn-4-en-3-one were $61,4,1.5$ and $1 \%$ respectively and with other steroids was $<1 \%$. Two hundred microlitres sample or standard $\left(0 \cdot 3-10 \cdot 0 \mathrm{ng}\right.$ progesterone $\mathrm{ml}^{-1}$, Sigma) was extracted in duplicate with $3 \mathrm{ml}$ di-ethylether (analar grade, May \& Baker, Dagenham, Essex, UK) by vortex mixing for 5 min on a multi-tube vortexer (SMI, Alpha Lab., Eastleigh, Hampshire, UK). Extraction efficiency was $79 \pm 6 \%$ $(n=8)$. The ether phase of each extract was decanted into a glass assay tube after freezing the aqueous phase in a methanol-dry-ice bath, and then dried under air. Iodinated tracer (provided by C. E. Gray, The Royal Infirmary, Glasgow, UK) was prepared by iodination of progesterone $11 \alpha$-glucuronyl tyramine and purified by solvent extraction and TLC (Corrie et al., 1981). Tracer ( $100 \mu \mathrm{l}$, approximately 10000 c.p.m.) and primary antiserum $(200 \mu \mathrm{l}$, $1: 20000$ ) were added and the tubes were incubated in a water bath at $37^{\circ} \mathrm{C}$ for $45 \mathrm{~min}$. Second antibody (donkey anti-sheep: goat gammaglobulin, 1:20 containing 1:200 normal goat serum, 400 $\mu$ l; SAPU, Law Hospital, Carluke, Strathclyde, UK) was added and incubated at $4^{\circ} \mathrm{C}$ overnight. Tubes were centrifuged at $2000 \mathrm{~g}$ for $15 \mathrm{~min}$ and the antibody-bound fraction was counted after the supernatant had been aspirated. Assay sensitivity was $0 \cdot 2 \pm 0 \cdot 1 \mathrm{ng}$ $\mathrm{ml}^{-1}(n=20)$. Inter- and intra-assay coefficients of variation for a plasma pool containing high progesterone concentration were 11 and $7 \%$, respectively.

Plasma oestradiol concentration was determined by double-antibody radioimmunoassay as described previously (Jeffcoate \& Lindsay, 1989). Assay sensitivity was $1 \cdot 0 \pm 0.5 \mathrm{pg} \mathrm{ml}^{-1}(n=10)$ and inter- and intra-assay coefficients of variation for a plasma pool containing high oestradiol concentration were 12 and $8 \%$, respectively.

A number of entire sampling sequences were assayed together but in random order in each hormone assay. Representative samples from previously assayed sample sequences were also reanalysed in later assays, in addition to the high and low plasma pools, for further interassay quality control.

\section{Statistical analysis}

Plasma L.H and oestradiol concentrations are presented untransformed. For oestradiol the overall mean concentration in sampling sequences grouped into intervals before the preovulatory LH peak is also shown. In addition, the integrated squared second derivative for log-transformed $\mathrm{LH}$ and oestradiol concentrations in each sampling sequence was obtained (MINITAB Inc.). This analysis provides an index of sample-to-sample variability and permits the fluctuations in hormone concentrations within $6 \mathrm{~h}$ sampling sequences to be quantified and compared.

\section{Results}

\section{Animals and sampling times}

Oestrous cycles were followed in two bitches from June 1987 and in another two from April 1988, until August 1989. One cycle was studied in the fifth bitch from June to December 1987. This resulted in 15 cycles being studied. The average cycle length (between pre-ovulatory LH peaks) was 168 days (range 140-219) and the cycles were approximately in synchrony with oestrus occurring during May and June and November and December each year. Vulvular bleeding was taken to indicate the start of pro-oestrus and was first observed on average 7 days before the preovulatory LH peak. A total of 35 sampling periods were conducted at times ranging from 185 to 1 day before the preovulatory LH peak as detailed in Table 1, together with the plasma progesterone concentration on the day of each sampling procedure. By following plasma progesterone concentrations, the reproductive status of the dogs on each of the 35 sampling occasions could be categorized into one of four phases: (1) luteal phase when plasma progesterone was high (>2.3 $\mathrm{ng} \mathrm{ml}^{-1}$, mean 6.9); (2) late luteal phase to transition to anoestrus when plasma progesterone concentration was either low but not basal (range 1.0-1.8 $\mathrm{ng} \mathrm{ml}^{-1}$, mean 1.4 ) or had been basal $\left(<0.8 \mathrm{ng} \mathrm{ml}^{-1}\right.$ ) for only a 
Table 1. Number of days before the preovulatory luteinizing hormone ( $\mathrm{LH}$ ) peak in beagle bitches, the cycle stage and plasma progesterone concentration when sampling sequences were collected

\begin{tabular}{|c|c|c|c|c|c|c|c|c|c|c|}
\hline \multirow[b]{2}{*}{ Bitch } & & \multicolumn{9}{|c|}{ Sampling sequence number } \\
\hline & & 1 & 2 & 3 & 4 & 5 & 6 & 7 & 8 & 9 \\
\hline \multirow[t]{3}{*}{ MI } & Days & 85 & 21 & 114 & 77 & 71 & 44 & 2 & 72 & 37 \\
\hline & Stage & A & A & LA & A & L & LA & $\mathbf{P}$ & LA & A \\
\hline & Progesterone ${ }^{a}$ & $0 \cdot 2$ & 0.4 & $0 \cdot 2$ & 0.4 & $3 \cdot 3$ & $1 \cdot 1$ & $1 \cdot 1$ & 1.0 & 0.3 \\
\hline \multirow[t]{3}{*}{03} & Days & 82 & 27 & 100 & 98 & 62 & 34 & 7 & 16 & 61 \\
\hline & Stage & A & A & LA & L & LA & A & $\mathrm{P}$ & A & LA \\
\hline & Progesterone $\mathrm{a}^{\mathrm{a}}$ & $0 \cdot 2$ & $0 \cdot 3$ & $0 \cdot 3$ & $9 \cdot 5$ & $0 \cdot 2$ & $0 \cdot 8$ & 1.5 & $0 \cdot 3$ & 0.2 \\
\hline \multirow[t]{3}{*}{46} & Days & 68 & 107 & 71 & 43 & 17 & 1 & 70 & 27 & - \\
\hline & Stage & A & L & LA & A & A & $\mathrm{P}$ & LA & A & - \\
\hline & Progesterone $^{a}$ & $0 \cdot 4$ & $9 \cdot 2$ & 1.8 & $1 \cdot 0$ & $1 \cdot 0$ & $3 \cdot 2$ & 1.7 & $0 \cdot 2$ & - \\
\hline \multirow[t]{3}{*}{92} & Days & 185 & 60 & 154 & 103 & 80 & 46 & 11 & - & - \\
\hline & Stage & A & A & $\mathrm{L}$ & LA & LA & A & A & - & - \\
\hline & Progesterone ${ }^{a}$ & $0 \cdot 3$ & 0.7 & $>10$ & $2 \cdot 3$ & 0.8 & $0 \cdot 3$ & $0 \cdot 2$ & - & - \\
\hline \multirow[t]{3}{*}{ A4 } & Days & 75 & 19 & - & - & - & - & - & - & - \\
\hline & Stage & LA & A & - & - & - & - & - & - & - \\
\hline & Progesterone $\mathrm{e}^{\mathrm{a}}$ & $0 \cdot 2$ & 0.5 & - & - & - & - & - & - & - \\
\hline
\end{tabular}

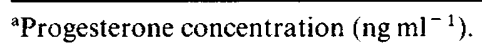

A: anoestrus; L: luteal phase; LA: luteal-anoestrus transition; P: pro-oestrus.

few days; (3) anoestrus when progesterone levels were basal (mean $0.4 \mathrm{ng} \mathrm{ml}^{-1}$ ); and (4) pro-oestrus when vulvular bleeding had started and when plasma progesterone concentrations were increasing again (range 1.3-3.0 $\mathrm{ng} \mathrm{ml}^{-1}$ ). The duration and timing of these major phases were not constant despite a fairly uniform cycle length. Consequently, although it was possible to determine whether a bitch was in the luteal phase or anoestrus on the basis of progesterone concentration, it was impossible to predict when pro-oestrus or the preovulatory LH peak would occur. The cycle stage at each sampling period therefore had to be calculated retrospectively after the day of the $\mathrm{LH}$ peak had been detected. The range in the number of days from sampling to LH peak for the four different cycle stages was as follows: luteal phase, day 154-71; luteal phase-anoestrus transition, day 114-44; anoestrus, day 85-11 (with one at 185 days (bitch 92 sequence 1)); pro-oestrus, day 7-1.

\section{Oestradiol and LH concentration}

Plasma LH and oestradiol concentration during various intensive sampling periods at representative stages of the cycles in four bitches are shown in Fig. 1. Spontaneous LH pulses were observed superimposed on basal levels during most sampling sequences throughout each cycle in each bitch. No consistent change in either mean $\log \mathrm{LH}$ concentration or $\mathrm{LH}$ variability within each sampling sequence was observed as the cycle progressed ( $\mathrm{LH}$ variability indices (mean $\pm \mathrm{SEM}, \log$ scale) for sample sequences collected during the luteal phase, transition to anoestrus, anoestrus and pro-oestrus were $0.57 \pm 0.08,0.57 \pm 0.14,0.64 \pm 0.11$ and $0.32 \pm 0.17$, respectively). Plasma oestradiol concentration was below assay sensitivity $\left(0.8 \mathrm{pg} \mathrm{ml}^{-1}\right)$ in most samples collected during the transition from the luteal phase to anoestrus and then during anoestrus until approximately one month before the LH peak. Thereafter, a pulsatile pattern of oestradiol secretion developed, although there still appeared to be low baseline levels (Fig. 1). Mean ( \pm SEM) oestradiol concentration was $1.4 \pm 0 \cdot 1,1 \cdot 3 \pm 0 \cdot 1,2 \cdot 4 \pm 0 \cdot 3,11 \cdot 0 \pm 1.4$ and $36.0 \pm 3.2 \mathrm{pg} \mathrm{m}^{-1}$ for sampling sequences falling into the periods $100-75,74-50,49-25,24-10$ and 9-1 days before LH peak respectively. Estimates of oestradiol variability in the same samples were $0 \cdot 19 \pm 0 \cdot 05,0 \cdot 18 \pm 0 \cdot 03$, $0.62 \pm 0.22,1.05 \pm 0.32$ and $0.15 \pm 0.03$ respectively (mean $\pm \mathrm{SEM}, \log$ scale). The mean oestradiol 
(a)

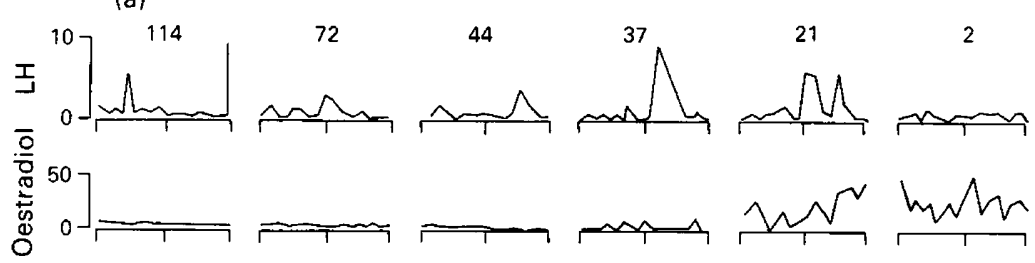

(b)

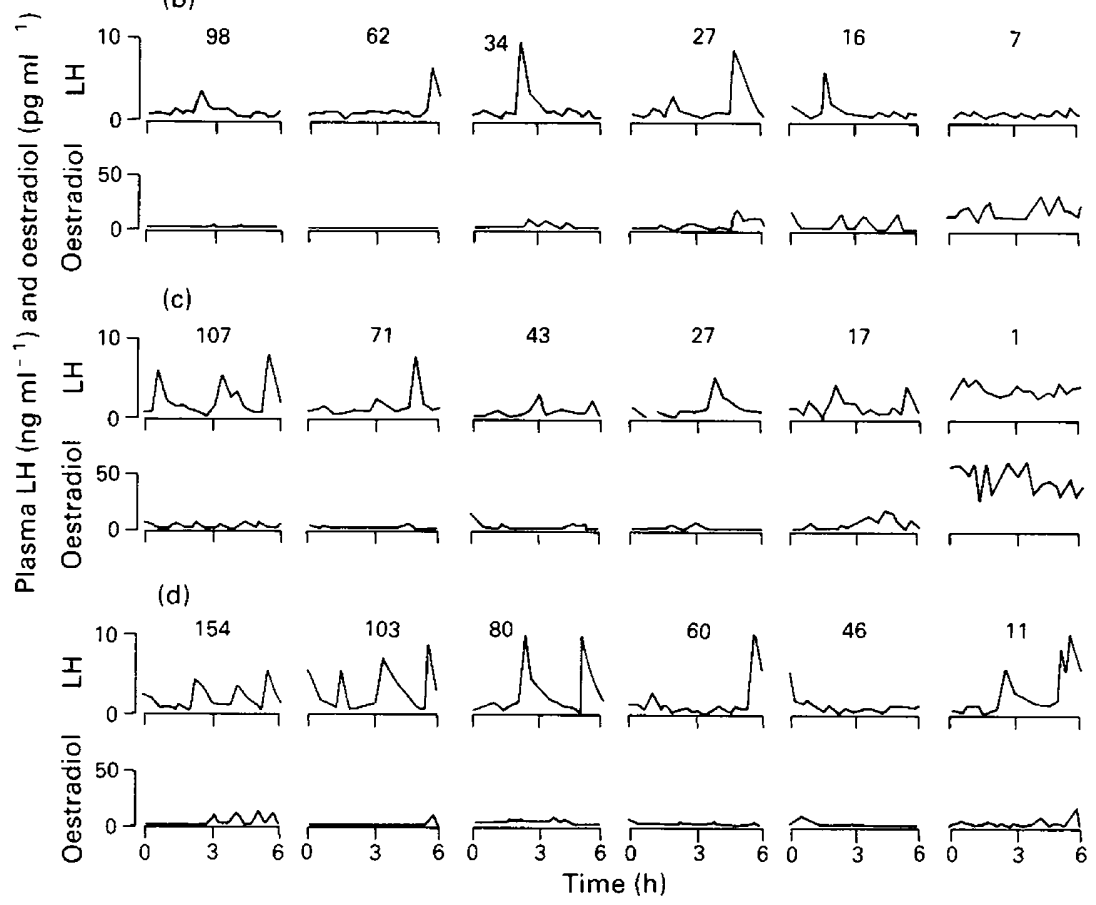

Fig. 1. Plasma luteinizing hormone (LH) and oestradiol concentrations in blood samples collected at $20 \mathrm{~min}$ intervals for $6 \mathrm{~h}$ at various representative stages of the oestrous cycles in bitches M1(a), O3(b), 46(c), 92(d). Number of days from sampling until the day of the preovulatory LH peak is shown above each data set. Cycle stage can be obtained from Table 1 using this number.

variability index for samples collected between 100 and 154 days before LH peak was $0 \cdot 6 \pm 0 \cdot 3$. Pulsatile oestradiol secretion therefore occurred during the luteal phase but tended to decrease during anoestrus and then to increase together with mean oestradiol concentrations from about one month before the LH peak. In the three sample sequences collected during pro-oestrus, oestradiol pulsatility was low, although plasma concentrations were high.

The dose of GnRH injected was selected to evoke $40 \%$ maximal $\mathrm{LH}$ release after single injection (1. A. Jeffcoate, unpublished). Injection of GnRH caused rapid increases in plasma LH concentration in each bitch and although there was some variability in response between animals, there was no apparent correlation between cycle stage and LH response. Overall mean ( \pm SEM) plasma LH concentration was maximal $10 \mathrm{~min}$ after injection $\left(12.5 \pm 1.0 \mathrm{ng} \mathrm{m}^{-1}\right)$ and had fallen to $5 \cdot 7 \pm 2 \cdot 5 \mathrm{ng} \mathrm{ml}^{-1} 60 \mathrm{~min}$ after injection. Changes in plasma oestradiol concentration in response to GnRH injection were less clear cut. Small increases in plasma oestradiol concentration (range 5-15 $\mathrm{p} \mathrm{m} \mathrm{m}^{-1}$ ) were identified from 40-60 min after injection in many instances until about a month before the pre-ovulatory LH peak. In these samples, baseline oestradiol levels had been generally 
below assay sensitivity before injection (see Fig. 1). During the last month before the pre-ovulatory LH peak, pre-injection plasma oestradiol concentration was often high or quite variable and it was not possible to differentiate the response to $\mathrm{GnRH}$ injection from the peripheral oestradiol concentrations.

\section{Discussion}

The length of the oestrous cycles of the dogs used in this study was normal for colony beagles. There was no evidence that GnRH treatment shortened the cycles, particularly since twice-daily injections of the same analogue and dose rate have been shown to induce pituitary LH secretion but not to shorten anoestrus (I. A. Jeffcoate, unpublished). The cycles appeared to be approximately synchronized but it is not known whether this was due to chance or to contact in the kennels. Since the experiment was concerned with the endocrine changes that accompany the onset of pro-oestrus rather than with cycle length per se, this effect was not considered important.

Spontaneous $\mathrm{LH}$ pulses were detected at each stage of the cycle and in almost every sample sequence except during pro-oestrus. No analysis of LH pulse frequency was attempted in this study, but Concannon et al. (1986b) studied samples collected frequently for $7 \mathrm{~h}$ from a larger group of dogs and showed that LH pulse frequency increased during anoestrus to a maximum in late anoestrus (25-10 days before the LH peak) of more than two pulses in $7 \mathrm{~h}$ in $75 \%$ of dogs, and then decreased again during pro-oestrus. Although a comparable frequency of LH pulses was observed in the present study, mean $\log$ LH concentrations and an index of LH variability did not reveal any tendency for LH secretion to change throughout anoestrus. In contrast, there were marked alterations in the pattern of oestradiol secretion as the cycle progressed. Mean plasma oestradiol concentrations and the variability index were low during anoestrus until about a month before the $\mathrm{LH}$ peak and then increased considerably. These results are different from other published reports which have shown high but somewhat variable plasma oestrogen values during canine anoestrus (e.g. Graf, 1978; Olson et al., 1982). However, these authors failed to find any manifestations of increased oestrogen concentrations on the reproductive tract or on sexual behaviour and could not explain the source or aetiology of such values. Also, vaginal endoscopy revealed no evidence of oestrogenic stimulation of the tract until late anoestrus (Lindsay, 1983) and other studies have clearly shown low but increasing plasma oestradiol concentrations preceding the onset of pro-oestrus (Jeffcoate \& Lindsay, 1989). It seems more probable that oestradiol concentration should be low during anoestrus because although antral follicles can be observed, they remain small (Concannon, 1986a). Nevertheless, it has been suggested that termination of anoestrus may in some bitches be associated with a number of waves of follicular development, which mostly end in atresia, but which might produce transient increases in plasma oestradiol concentrations (Concannon, 1986a). Higher plasma oestradiol concentrations were recorded during the late luteal phase and transition into anoestrus than during the bulk of anoestrus (although overall the means are not different) and it would appear that the source of oestrogen at this time is the ageing corpora lutea (Fowler \& Feldman, 1970). Progesterone can be detected in blood samples collected during anoestrus; this finding has previously been noted and ascribed to adrenal progesterone secretion (Concannon, 1986a). Progesterone concentration then increased during pro-oestrus, possibly as a result of follicular activity.

Endogenous LH pulses were quite evident in the present study during early to mid-anoestrus and a standard dose of GnRH stimulated comparable pituitary LH release at each stage of the cycle. Additionally, plasma FSH concentrations have been shown to be increased during anoestrus (Olson et al., 1982). There is evidence therefore that anoestrus is not brought about by insufficient circulating or releasable gonadotrophins. However, the fact that very few spontaneous increases in plasma oestradiol concentration were detected during early to mid-anoestrus suggests that ovarian responsiveness to gonadotrophins is low at this time. This could be a consequence of unsuitable 
numbers of follicles on the ovaries or to follicular insensitivity to LH. The presence of low but detectable plasma oestradiol levels after GnRH-induced LH release possibly contradicts this theory, but it should be emphasized that the amplitude and duration of induced LH release were greater than that observed spontaneously, probably because of the long half-life of this synthetic analogue (Swift \& Crighton, 1979). As to the possibility that ovarian responsiveness is low during early and mid-anoestrus, prolactin has been implicated in reducing ovarian responsiveness to gonadotrophins and also gonadotrophin secretion during anoestrous situations in other species (McNeilly, 1987). In this context, it is interesting to note that prolactin levels are increased early in canine anoestrus and remain detectable throughout anoestrus, and also that inhibition of prolactin secretion may possibly shorten anoestrus (Okkens et al., 1985; Jochle et al., 1989). Further work should therefore address the relationship between $\mathrm{LH}$, oestradiol and prolactin during the transition between anoestrus and pro-oestrus. The present results suggest that this transitional period can be identified by increases in plasma oestradiol concentration.

This work was funded by a grant from The Wellcome Trust. I am grateful to C. E. Gray, A. M. Wallace and B. Cook for materials and advice for assay development; L. E. Reichert and The National Hormone and Pituitary Program (NIADDK), University of Maryland School of Medicine, Baltimore, Maryland, USA for purified gonadotrophin preparations and G. D. Niswender for LH antiserum. I thank G. Jackson for expert help, the staff of The Wellcome Surgical Unit for care of the animals and G. Murray, Department of Medical Statistics, Western Infirmary, Glasgow for help with statistical analysis.

\section{References}

Concannon, P.W. (1986a) Canine physiology of reproduction. In Small Animal Reproduction and Fertility: A Clinical Approach to Diagnosis and Treatment, pp. 23-77. Ed. T. J. Burke. Lea and Febiger, Philadelphia.

Concannon, P.W. (1986b) Increased LH pulse frequency associated with termination of anoestrus during the ovarian cycle of the dog. Biol. Reprod. 34, Suppl. 1, 109.

Corrie, J.E.T., Hunter, W.M. \& Macpherson, J.S. (1981) A strategy for radioimmunoassay of plasma progesterone with use of a homologous-site ${ }^{125}$ I-labelled radioligand. Clin. Chem. 27, 594-599.

Fowler, E.H. \& Feldman, M.K. (1970) Histochemical demonstration of hydroxysteroid dehydrogenase activity in the mature canine ovary. Gen. \& comp. Endocr. 14, 484.496.

Graf, K-J. (1978) Serum oestrogen, progesterone and prolactin concentrations in cyclic, pregnant and lactating beagle dogs. J. Reprod. Fert 52, 9-14.

Hadley, J.C. (1975) Total unconjugated oestrogen and progesterone concentrations in peripheral blood during the oestrous cycle of the dog. J. Reprod. Fert. 44, 445-451.

Jeffcoate, I.A. \& Lindsay, F.E.F. (1989) Ovulation detection and timing of artificial insemination based on hormone concentrations, vaginal cytology and the endoscopic appearance of the vagina in domestic bitches. J. Reprod. Fert. Suppl. 39, 277-287.

Jochle, W., Arbeiter, K., Post, K., Ballabio, R. \& D'Ver, A.S. (1989) Effects on pseudopregnancy, pregnancy and interoestrous intervals of pharmacological suppression of prolactin secretion in female dogs and cats. J. Reprod. Fert. Suppl. 39, 199-207.

Lance, V.A., Murphy, W.A., Sueiras-Diaz, J. \& Coy, D.H. (1984) Super-active analogs of growth hormonereleasing factor (1-29) amide. Biochem. Biophys. Res. Commun. 119, 265-272.

Lindsay, F.E.F. (1983) The normal endoscopic appearance of the caudal reproductive tract of the cyclic and non-cyclic bitch: post-uterine endoscopy. J. Small Anim. Pract. 24, 1-15.

McNeilly, A.S. (1987) Prolactin and the control of gonadotrophin secretion. J. Endocr. 115, 1-5.

Nett, T.M., Akbar, A.M., Phemister, R.D., Holst, P.A., Reichert, L.E. \& Niswender, G.D. (1975) Levels of luteinizing hormone, estradiol and progesterone in serum during the estrous cycle and pregnancy in the beagle bitch. Proc. Soc. exp. Biol. Med. 148, 134-139.

Okkens, A.C., Bevers, M.M., Dieleman, S.J. \& Willemse, A.H. (1985) Shortening of the interoestrous interval and the lifespan of the corpus luteum of the cyclic dog by bromocryptine treatment. Vet. Quart. 7, 173-176.

Olson, P.N., Bowen, R.A., Behrendt, M.D., Olson, J.D. \& Nett, T.M. (1982) Concentrations of reproductive hormones in canine serum throughout late anestrus, proestrus and estrus. Biol. Reprod. 27, 1196-1206.

Swift, A.D. \& Crighton, D.B. (1979) Relative activity, plasma elimination and tissue degradation of synthetic luteinizing hormone releasing hormone and certain of its analogues. J. Endocr. 80, 141 152 .

Received 7 January 1991 